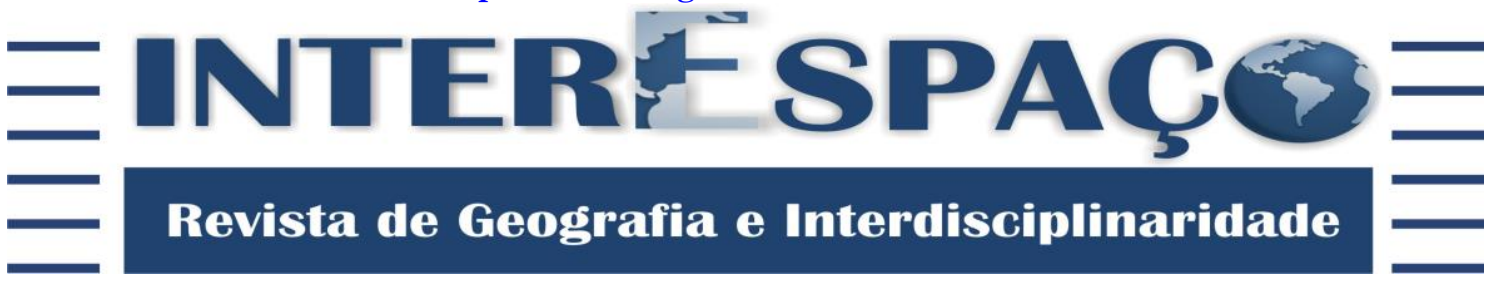

\section{PERCEPÇÃO AMBIENTAL QUANTO AO GERENCIAMENTO DE RESÍDUOS SÓLIDOS DOMICILIARES: estudo de caso da} cidade de Mamborê, Paraná

\author{
ENVIRONMENTAL PERCEPTION ON THE MANAGEMENT OF \\ DOMICILIARY SOLID RESIDUES: case study of the Mamborê city, Paraná \\ PERCEPCIÓN AMBIENTAL CUANTO A LA GESTIÓN DE RESIDUOS \\ SÓLIDOS DOMICILIARES: estudio de caso de la ciudad de Mamboré, Paraná
}

\begin{abstract}
Silvana de Jesus Galdino
Geógrafa, Doutoranda pelo Programa de Pós Graduação em Geografia da Universidade Estadual de Maringá - UEM. silgaldino@outlook.com / http://orcid.org/0000-0002-7785-7630

Maila Mirian Ferreira de Carvalho

Geógrafa, Graduada em Geografia pela Universidade Estadual do Paraná - Campus de Campo Mourão. millamf_ferreira@hotmail.com / http:/ /orcid.org/0000-0003-0080-3164
\end{abstract}

Recebido para avaliação em 03/07/2018; Aceito para publicação em 13/03/2019.

\section{RESUMO}

O crescimento da população urbana juntamente com o consumismo exagerado tem gerado a escassez dos recursos naturais, aumento da quantidade e diversidade de resíduos descartados diretamente na natureza, sem qualquer tipo de tratamento prévio. Sendo assim, adotar medidas para minimizar os impactos ambientais e socioeconômicos decorrentes da ausência ou deficiência na gestão e gerenciamento dos resíduos tornou-se problema na maioria das cidades brasileiras. Isso está diretamente relacionado à falta de infraestrutura adequada, equipe técnica qualificada, equipamentos e escassez de recursos necessários à gestão integrada dos Resíduos Sólidos Urbanos. Diante da problemática apresentada, esse artigo teve por objetivo apresentar um diagnóstico da percepção que os moradores da cidade de Mamborê-PR têm acerca da temática resíduos sólidos domiciliares. Para tanto, fez-se necessário revisão bibliográfica e levantamento de informações junto à prefeitura municipal e população, através de entrevistas semiestruturadas e questionário com perguntas fechadas. Durante levantamento de dados, constatou-se que, o município coleta $11.671 \mathrm{~kg} \mathrm{dia}^{-1}$, ou seja, 0,835 $\mathrm{kg} /$ hab-1.dia-1, com cobertura de aproximadamente $100 \%$ dos domicílios da área urbana, no entanto, as maiores dificuldades estão em gerenciar adequadamente os resíduos de forma a desenvolver ações de incentivo à coleta seletiva com base no Decreto $n^{\circ} 7.405 / 2010$ e promover a valorização do trabalho dos coletores e catadores de resíduos sólidos urbanos. Dentre as deficiências encontradas no gerenciamento dos resíduos sólidos domiciliares de Mamborê-PR está a falta de segregação e acondicionamento diretamente na fonte geradora, pois $55,3 \%$ da população entrevistada na área central e áreas periféricas disponibilizam os resíduos para coleta seletiva em mesmo recipiente da coleta convencional. Diante das dificuldades apontadas, a pesquisa poderá contribuir na elaboração de ações conjuntas para a elaboração do Plano de Gerenciamento Integrado dos Resíduos Sólidos.

Palavras-chave: Resíduos Sólidos; Coleta Seletiva; Educação Ambiental.

\section{ABSTRACT}


| Percepção ambiental quanto ao gerenciamento de resíduos sólidos domiciliares: estudo de caso da cidade de Mamborê, Paraná|

\section{| Silvana de Jesus Galdino | Maila Mirian Ferreira Carvalho |}

The growth of the urban population together with the exaggerated consumerism has generated the scarcity of natural resources, an increase in the quantity and diversity of waste disposed of directly in nature, without any type of previous treatment. Therefore, adopting measures to minimize the environmental and socioeconomic impacts resulting from absence or deficiency in waste management and management has become a problem in most Brazilian cities. This is directly related to the lack of adequate infrastructure, qualified technical staff, equipment and scarcity of resources necessary for the integrated management of the Solid Waste Us. In view of the presented problem, this article had the objective of presenting a diagnosis of the perception that the residents of the city of Mamborê-PR have on the subject of solid residues domiciliares. In order to do so, it was necessary to review the bibliography and collect information from the municipal government and the population, through semi-structured interviews and questionnaires with closed questions. During data collection, it was found that the municipality collected $11,671 \mathrm{~kg}$ day- 1 , that is, $0.835 \mathrm{Kg} / \mathrm{hab}-$ 1.dia-1, with coverage of approximately $100 \%$ of the urban area households, however, the greatest difficulties are in adequately managing the waste in order to develop incentive actions for selective collection based on Decree No. 7,405/2010 and to promote the valuation of the work of collectors and waste collectors. Among the deficiencies found in the management of solid residues in Mamborê-PR is the lack of segregation and conditioning directly in the generating source, since $55.3 \%$ of the population interviewed in the central area and peripheral areas dispose the waste for selective collection in the same container of the conventional collection. Given the difficulties mentioned above, the research may contribute to the elaboration of joint actions for the elaboration of the Integrated Management Plan for Solid Waste.

Keywords: Solid Waste; Selective Collect; Environmental Education.

\section{RESUMEN}

El crecimiento de la población urbana junto con el consumismo exagerado ha generado la escasez de recursos naturales, aumento de la cantidad y diversidad de residuos descartados directamente en la naturaleza, sin ningún tipo de tratamiento previo. Por lo tanto, adoptar medidas para minimizar los impactos ambientales y socioeconómicos derivados de la ausencia o deficiencia en la gestión y gestión de los residuos se ha convertido en un problema en la mayoría de las ciudades brasileñas. Esto está directamente relacionado con la falta de infraestructura adecuada, equipo técnico cualificado, equipos y escasez de recursos necesarios para la gestión integrada de los Residuos Sólidos Urbanos. Ante la problemática presentada, ese artículo tuvo por objetivo presentar un diagnóstico de la percepción que los moradores del ciudad de Mamborê-PR tienen acerca de la temática residuos sólidos domiciliarios. Para ello, se hizo necesaria revisión bibliográfica y levantamiento de informaciones sobre la alcaldía municipal y la población, a través de entrevistas semiestructuradas y cuantitativas con preguntas cerradas. Durante el levantamiento de datos, se constató que, el municipio recolecta $11.671 \mathrm{~kg}$ día-1, o sea, $0,835 \mathrm{Kg} / \mathrm{hab}-1$.dia-1, con cobertura de aproximadamente el $100 \%$ de los domicilios del área urbana, sin embargo, las mayores dificultades están en administrar adecuadamente los residuos de forma a desarrollar acciones de incentivo a la recolección selectiva con base en el Decreto $\mathrm{n}^{\circ} 7.405 / 2010$ y promover la valorización del trabajo de los recolectores y recolectores de residuos sólidos urbanos. Entre las deficiencias encontradas en el manejo de los residuos sólidos domiciliarios de Mamborê-PR está la falta de segregación y acondicionamiento directamente en la fuente generadora, pues el 55,3\% de la población entrevistada en el área central y áreas periféricas disponibilizan los residuos para colecta selectiva en el mismo recipiente de la misma, colecta convencional. En el marco de las dificultades señaladas, la investigación podrá contribuir en la elaboración de acciones conjuntas para la elaboración del Plan de Gestión Integrada de los Residuos Sólidos.

Palabras clave: Residuos Solidos; Recogida Selectiva; Educación Ambiental.

\section{INTRODUÇÃO}


| Percepção ambiental quanto ao gerenciamento de resíduos sólidos domiciliares: estudo de caso da cidade de Mamborê, Paraná|

| Silvana de Jesus Galdino | Maila Mirian Ferreira Carvalho|

Gerenciar de forma integrada os resíduos gerados no meio urbano tem sido um dos grandes desafios para a sociedade moderna, pois consiste em um conjunto articulado de ações normativas, operacionais, financeiras e de planejamento. Todavia, o manejo irregular dos resíduos sólidos urbanos gera vários impactos negativos ao meio ambiente, à economia do sistema de reciclagem e à qualidade de vida dos habitantes. Logo, torna-se necessário conhecer a gestão e gerenciamento dos resíduos sólidos, com o intuito de obter dados para a comunidade científica e auxiliar na implantação de políticas públicas municipais.

Segundo Bidone e Povinelli (1999), o termo "lixo" significa tudo que não pode ser reaproveitado ou reciclado, e resíduos sólidos são materiais heterogêneos, resultantes das atividades humanas e da natureza, os quais podem ser parcialmente ou totalmente utilizados. Normalmente o primeiro está associado às questões de ordem social e econômica, enquanto o segundo está ligado às questões técnicas de origem, composição e disposição.

Com base na Política Nacional de Resíduos Sólidos, Lei No 12.305 de 02 de agosto de 2010 (BRASIL, 2010, p. 03), os resíduos sólidos são definidos como "material, substância, objeto, ou bem descartado, resultante de atividades humanas em sociedade, a cuja destinação, se procede, se propõe a proceder, ou se está obrigado a proceder, nos estados sólidos ou semissólidos".

A Lei $N^{o}$ 12.305, de 02 de agosto de 2010 (BRASIL, 2010), define rejeitos como resíduos sólidos que, depois de esgotadas todas as possibilidades de tratamento, recuperação por processos tecnológicos disponíveis e economicamente viáveis, não apresentem outra possibilidade que não a disposição final ambientalmente adequada. Portanto, a abordagem do problema deve se iniciar pela não geração, redução, reaproveitamento, reciclagem, tratamento e, por último, a destinação final ambientalmente correta (BRASIL, 2010, art. $9^{\circ}$ ).

Conforme dados da ABRELPE (2016, p. 15), a população brasileira apresentou um crescimento de 0,8\% entre 2015 e 2016, enquanto a geração per capita de RSU (Resíduos Sólidos Urbanos) registrou queda de 3\% no mesmo período. A geração total de resíduos sofreu queda de $2 \%$ e chegou a 214.405 t/dia de RSU gerados no país. Todavia, os índices de disposição final ambientalmente adequada apresentaram retrocesso, uma vez que as unidades inadequadas como lixões e aterros controlados ainda estão presentes em todas as regiões do país e receberam mais de 81 mil toneladas de resíduos por dia, com elevado potencial de poluição ambiental e impactos negativos na saúde (ABRELPE, 2016).

Ainda de acordo com os dados do Panorama dos Resíduos Sólidos no Brasil (ABRELPE, 2016), a cobertura dos serviços de coleta de RSU passou de 90,8\% para 91,2\% 
| Percepção ambiental quanto ao gerenciamento de resíduos sólidos domiciliares: estudo de caso da cidade de Mamborê, Paraná|

| Silvana de Jesus Galdino | Maila Mirian Ferreira Carvalho|

do volume gerado, no entanto, a coleta seletiva não avançou na mesma proporção e hoje só temos iniciativas registradas em $69,6 \%$ das cidades. A consequência direta disso são os índices de reciclagem que se mostram estagnados há alguns anos, apesar da grande propaganda que tem sido feita a esse respeito.

Nesse contexto, distinguir os diversos tipos de resíduos gerados é de fundamental importância para determinar a melhor forma de tratamento, aproveitamento e destinação final. A classificação é relevante para a escolha de estratégia de gerenciamento viável. Em função desta classificação será realizado o planejamento das decisões que devem ser desenvolvidas e executadas na prática.

Sendo assim, a segregação diretamente na fonte geradora evita que os resíduos se contaminem, contribui para aumentar a quantidade e qualidade dos resíduos recicláveis e orgânicos, valorizar o mercado de recicláveis, além de facilitar o processo de transporte, armazenamento e destinação final (ALBUQUERQUE, 2008; JUNIOR, 2003).

Outro fator é o acondicionamento dos resíduos, ou seja, dispor os mesmos em recipientes apropriados de maneira a facilitar sua coleta, de forma sanitariamente correta e compatível com o tipo e a quantidade de resíduo. Durante o acondicionamento dos resíduos deve-se levar em consideração a natureza dos resíduos, o destino, forma de recolhimento e as características do veículo a ser utilizado para transporte (MONTEIRO, 2001).

A maneira como se processa os serviços de coleta e transporte dos resíduos sólidos dependerá das condições de separação, armazenamento e acondicionamento dos mesmos, bem como, da disposição dos recipientes em dias e horários estabelecidos.

Os resíduos sólidos potencialmente perigosos presentes em resíduos sólidos domiciliares não devem ter o mesmo encaminhamento dos resíduos sólidos destinados à coleta convencional, sendo necessária a separação, acondicionamento, coleta, transporte, tratamento e destinação final de maneira diferenciada para que não gere passivos ambientais, ou até mesmo transtornos à coleta seletiva.

Para tanto, a contribuição dos geradores para com a coleta seletiva e convencional torna-se fundamental, uma vez que, essa coleta visa o recolhimento dos materiais diretamente na fonte geradora, havendo a necessidade do envolvimento da comunidade no processo. A coleta seletiva deve fazer parte de um sistema amplo de gestão integrada de resíduos sólidos.

Quanto ao valor social e econômico, a reciclagem tem se configurado como: alternativa para a contenção da exploração dos recursos naturais; diminuição na contaminação do ar, solo, água e melhorias na qualidade de vida do ser humano; reduz os 
| Percepção ambiental quanto ao gerenciamento de resíduos sólidos domiciliares: estudo de caso da cidade de Mamborê, Paraná|

| Silvana de Jesus Galdino | Maila Mirian Ferreira Carvalho|

desperdícios e gastos com limpeza urbana, além de gerar emprego e renda nas associações e cooperativas de catadores de materiais recicláveis.

Diante do exposto, a presente pesquisa teve como objetivo realizar um diagnóstico da percepção ambiental dos moradores da cidade de Mamborê-PR quanto ao gerenciamento dos resíduos sólidos gerados nas residências.

\section{ÁREA DE ESTUDO}

A presente pesquisa foi realizada no município de Mamborê-PR, localizado na Mesorregião Centro-Ocidental Paranaense, a $481 \mathrm{~km}$ de distância da capital do estado (IPARDES, 2011). Apresenta aproximadamente $782 \mathrm{~km}^{2}$ de área no terceiro planalto paranaense, à $980 \mathrm{~m}$ de altitude, com população de 13.968 habitantes, destes 8.988 residem na área urbana, de acordo com estimativas do Instituto Brasileiro de Geografia e Estatística (IBGE, 2010).

De acordo com dados do IPARDES (2011), o município faz parte da Microrregião Homogênea 286 e pertence à COMCAM - Comunidade dos Municípios da Região de Campo Mourão. O clima do município é do tipo Cfa ou Subtropical Úmido, sendo a média pluviométrica anual de $1.500 \mathrm{~mm}$ e média de temperatura de $20^{\circ} \mathrm{C}$.

De acordo com dados disponibilizados pelo IBGE (2010), o município possui 3.035 domicílios no perímetro urbano e 1.591 domicílios distribuídos pela zona rural, incluindo distrito Guarani e pequenas comunidades rurais no entorno. Possui renda média domiciliar per capita de $\mathrm{R} \$ 607,00$, com população economicamente ativa de 6.773 habitantes, grau de urbanização em torno de 65,61\% e IDHM de 0,71.

\section{METODOLOGIA}

A educação ambiental tem por objetivo despertar para a conscientização e o sentimento de preservar o ambiente. Portanto, para adotar soluções possíveis que possam resolver ou minimizar os problemas relacionados à gestão e gerenciamento dos resíduos sólidos urbanos devem-se considerar os diferentes comportamentos do ser humano perante esse ambiente.

Nesse contexto, a educação ambiental é de fundamental importância para compreensão da realidade local, como os indivíduos percebem e interagem com o ambiente no qual estão inseridos, as satisfações e insatisfações quanto aos serviços ofertados. Nesse sentido, a pesquisa foi realizada por meio de questionários aplicados nas áreas central e 
| Percepção ambiental quanto ao gerenciamento de resíduos sólidos domiciliares: estudo de caso da cidade de Mamborê, Paraná|

| Silvana de Jesus Galdino | Maila Mirian Ferreira Carvalho|

periféricas da cidade de Mamborê-PR, no intuito de entender como se dá a participação dos moradores no processo de gerenciamento dos resíduos sólidos gerados nas residências.

O levantamento dos dados e diagnóstico da relação que os moradores estabelecem com a geração de resíduos sólidos foram realizados envolvendo todas as áreas do perímetro urbano do município, ou seja, todas as classes socioeconômicas e respectivos dados demográficos. Para tanto, utilizou-se o contato direto com os moradores, através da aplicação de questionários com perguntas de múltipla escolha e discursiva, entendendo o contexto em que os moradores estão inseridos, conhecendo suas opiniões, o papel exercido quanto ao manejo adequado dos resíduos sólidos domiciliares e se estão cientes dos problemas decorrentes do tratamento e disposição final dos resíduos.

Através da aplicação dos questionários e observações direta da realidade foi possível investigar as relações que os moradores possuem com seu ambiente vivencial, hábitos e costumes quanto ao manejo do "lixo" em suas residências. Esse diagnóstico da percepção ambiental é essencial para que possamos compreender melhor as interações entre o homem e o ambiente, compreender suas expectativas, satisfações e insatisfações.

O tamanho da amostra foi calculado aplicando-se regra para o cálculo de amostras para proporções, considerando-se o fator de correção para populações finitas, por meio da adaptação da seguinte fórmula da Equação 1:

$$
n=\frac{z^{2} p q N}{z^{2} p q+(N-1) E^{2}}
$$

Considerou-se um nível de confiança $(1-\alpha)$ de $95 \%$, um erro (E) de 4\%, p=0,5 e $\mathrm{N}=3035$ domicílios, que compõem o total de domicílios da área urbana do município. Levando em consideração que os resíduos gerados poderiam apresentar diferenças em relação aos bairros, a cidade foi dividida em três estratos populacionais, sendo eles: área central, representada pela cor vermelha, áreas periféricas 1 , representada pela cor azul, e áreas periféricas 2, representada pela cor amarela.

Após a coleta de dados, as respostas obtidas foram classificadas com base nas três áreas da cidade (Figura 1). Na área central foram aplicados 316 questionários; nas áreas periféricas 1, que representa os conjuntos habitacionais, foram aplicados 95 questionários; nas áreas periféricas 2, representando os lugares mais carentes da cidade, foram aplicados 85 questionários, totalizando 496 questionários. Trata-se de 35 questões referentes ao comportamento dos moradores quanto aos resíduos sólidos gerados nos domicílios. 
| Percepção ambiental quanto ao gerenciamento de resíduos sólidos domiciliares: estudo de caso da cidade de Mamborê, Paraná|

| Silvana de Jesus Galdino | Maila Mirian Ferreira Carvalho|

Figura 1 - Perímetro urbano de Mamborê-PR e respectivas áreas selecionadas para aplicar os questionários

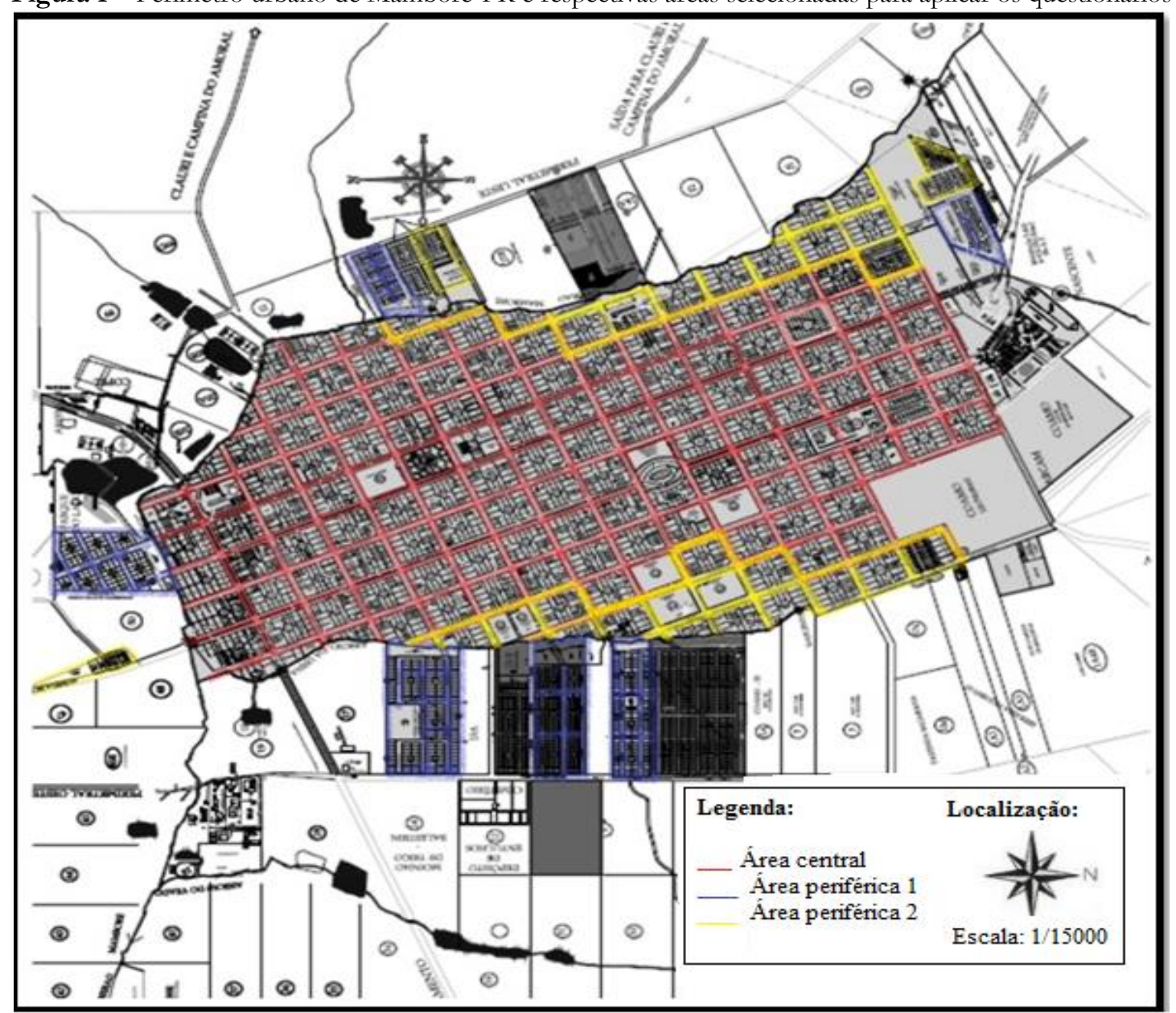

Fonte: Adaptado do Plano Diretor Municipal (2014).

Todos os moradores entrevistados assumiram serem os responsáveis pelo acondicionamento e armazenamento dos resíduos no domićlíio. A análise dos resultados estatísticos foi de cunho qualitativo e quantitativo, com objetivo de estabelecer o perfil dos moradores quanto à percepção ambiental.

Após o levantamento dos dados demográficos, analisou-se a opinião dos entrevistados quanto aos serviços prestados pela prefeitura do município para a coleta dos resíduos sólidos domiciliares, o quanto consideram ótimo, bom, regular, ruim ou péssimo e a quantidade de vezes que são coletados os resíduos durante a semana e se consideram suficiente.

A presente pesquisa levou em consideração também a opinião dos entrevistados quanto aos serviços prestados pela prefeitura do município para a coleta dos resíduos sólidos domiciliares, o quanto consideram ótimo, bom, regular, ruim ou péssimo e a quantidade de vezes que são coletados os resíduos durante a semana e se consideram suficiente, com intuito de obter informações sobre a contribuição por parte da prefeitura para o processo de reciclagem. 
| Percepção ambiental quanto ao gerenciamento de resíduos sólidos domiciliares: estudo de caso da cidade de Mamborê, Paraná|

| Silvana de Jesus Galdino | Maila Mirian Ferreira Carvalho|

Após aplicação dos questionários, juntamente com a população, procedeu-se com a entrevista informal junto à Secretaria do Meio Ambiente do município, no intuito de compreender o processo de coleta, transporte e destinação dos resíduos sólidos gerados nas residências. Durante entrevista foram apontadas possíveis alternativas para melhoria no sistema de gerenciamento dos resíduos, visando uma maior sensibilização ambiental, gestão participativa e integrada junto à comunidade e escolas.

\section{RESULTADOS E DISCUSSÃO}

A Lei $N^{\circ}$ 9.795, de 27 de abril de 1999, dispõe sobre a educação ambiental e institui a Política Nacional de Educação Ambiental, definindo-a como sendo os processos através dos quais o indivíduo e a coletividade constroem valores sociais, conhecimentos, habilidades, atitudes e competências focados na conservação do meio ambiente, bem de uso comum do povo essencial à sadia qualidade de vida e sua sustentabilidade. Sendo assim, os estudos envolvendo a relação do homem com a natureza são de grande importância para a busca de soluções dos problemas ambientais gerados pela ação do homem, uma vez que, o meio ambiente tem sofrido diversas modificações com o passar dos anos, em proporções cada vez maiores gerando degradação em grande escala.

Com base nos dados obtidos para a presente pesquisa, obtivemos os seguintes resultados:

Entre os dados demográficos dos entrevistados, obtivemos uma participação de 60\% das mulheres e 40\% dos homens, levando em consideração que os questionários foram aplicados no período matutino e vespertino, havendo assim uma maior participação das mulheres, comparado com os homens, uma vez que, estas passam maior parte do tempo em seus domicílios nesses períodos.

Já a faixa etária dos participantes entrevistados, foi bastante diversificada, compreendeu um universo diverso de idades, optando assim pelo agrupamento dos participantes. Desta forma, identificou-se a predominância de pessoas na faixa etária com idade superior a 60 anos de idade, obtendo uma participação de $28 \%$ entre os entrevistados, de 18 a 29 anos com $28 \%$, de 30 a 39 anos com $20 \%$, de 40 a 49 anos com $15 \%$ e, de 50 a 59 anos com $9 \%$ entre os entrevistados.

No que diz respeito ao número de moradores, em média, 37\% dos domićlíos selecionados para a pesquisa têm dois moradores, $42 \%$ têm três moradores, $13 \%$ possui quatro moradores ou mais e $8 \%$ dos informantes moram sozinhos. Percebe-se a 
| Percepção ambiental quanto ao gerenciamento de resíduos sólidos domiciliares: estudo de caso da cidade de Mamborê, Paraná|

| Silvana de Jesus Galdino | Maila Mirian Ferreira Carvalho|

predominância de três moradores por residência, dados estes que condizem com o levantamento realizado pelo Instituto Brasileiro de Geografia e Estatística (IBGE, 2010).

Em relação à opinião dos entrevistados sobre a participação da prefeitura na coleta de resíduos sólidos no município, 61,39\% dos informantes da área central consideram os serviços prestados pela prefeitura do município como bom, 54,74\% dos informantes residentes na área periférica 1 consideram a coleta como boa, e na área periférica 2, 49,41\% consideram como bom. Os demais participantes consideram os serviços prestados como regular, ruim ou péssimo. A maior porcentagem de indivíduos que consideram a prestação de serviços da prefeitura como bom reside na área central. Isso está atrelado à atenção dada pelo poder público, uma vez que, as coletas são realizadas com mais frequência na área central do município.

Quando foram questionados a respeito dos horários em que disponibilizam os materiais para a coleta, constatou-se que em média 12,19\% dos entrevistados disponibilizam um dia antes, $16,47 \%$ durante a noite, $18,20 \%$ à tarde e 53,11\% na parte da manhã. No entanto, na maioria dos casos os materiais são disponibilizados no mesmo dia e horário, juntamente com os resíduos destinados à coleta convencional.

Quando a disposição é realizada no mesmo dia e horário da coleta convencional, sem a separação adequada, ambos são encaminhados ao aterro sem nenhum tipo de tratamento prévio, justificando a porcentagem de mais de $60 \%$ da área das valas ocupadas por materiais potencialmente recicláveis, diminuindo a vida útil e dificultando o processo de manutenção.

A respeito dos horários que disponibilizam os resíduos da coleta convencional, $49 \%$ relataram que dispõe os resíduos na parte da manhã no dia da coleta e 51\% dispõe no dia anterior, durante a noite ou em qualquer horário. Entretanto, a disposição dos resíduos sólidos em qualquer horário é um fator negativo, pois pode atrair animais roedores, causar mau cheiro e poluição visual; quando estes se encontram misturados com os materiais recicláveis gera certo incômodo aos coletores e catadores. Sendo assim, dispor de horários bem definidos para disposição dos resíduos orgânicos e recicláveis torna-se fundamental. Todavia, o município não dispõe de coleta seletiva, com horários e rotas bem definidas, isso reflete no comportamento da população.

Ao serem indagados sobre a existência de coleta seletiva no seu bairro, 98,42\% dos entrevistados da área central destacaram que sim, 85,88\% dos moradores das áreas periféricas (2) e 100\% dos entrevistados das áreas periféricas (1), também disseram que sim. Todavia, a maior parte da coleta é realizada por catadores autônomos (Gráfico 1), 44,71\% 
| Percepção ambiental quanto ao gerenciamento de resíduos sólidos domiciliares: estudo de caso da cidade de Mamborê, Paraná|

| Silvana de Jesus Galdino | Maila Mirian Ferreira Carvalho|

dos entrevistados das áreas periféricas (2), 58,95\% nas áreas periféricas (1) e 34,18\% da área central.

No Gráfico 1 é possível identificar as diferentes formas de coleta dos materiais recicláveis da cidade de Mamborê-PR, com destaque para a porcentagem de catadores autônomos que realizam o trabalho, sem nenhum vínculo empregatício ou ajuda por parte da prefeitura. Como mostra o Gráfico 1, 58,95\% dos informantes das áreas periféricas (1) relataram que a coleta dos materiais recicláveis nos domicílios é realizada por catadores autônomos.

Gráfico 1 - Opinião dos entrevistados quanto à coleta dos recicláveis nas residências

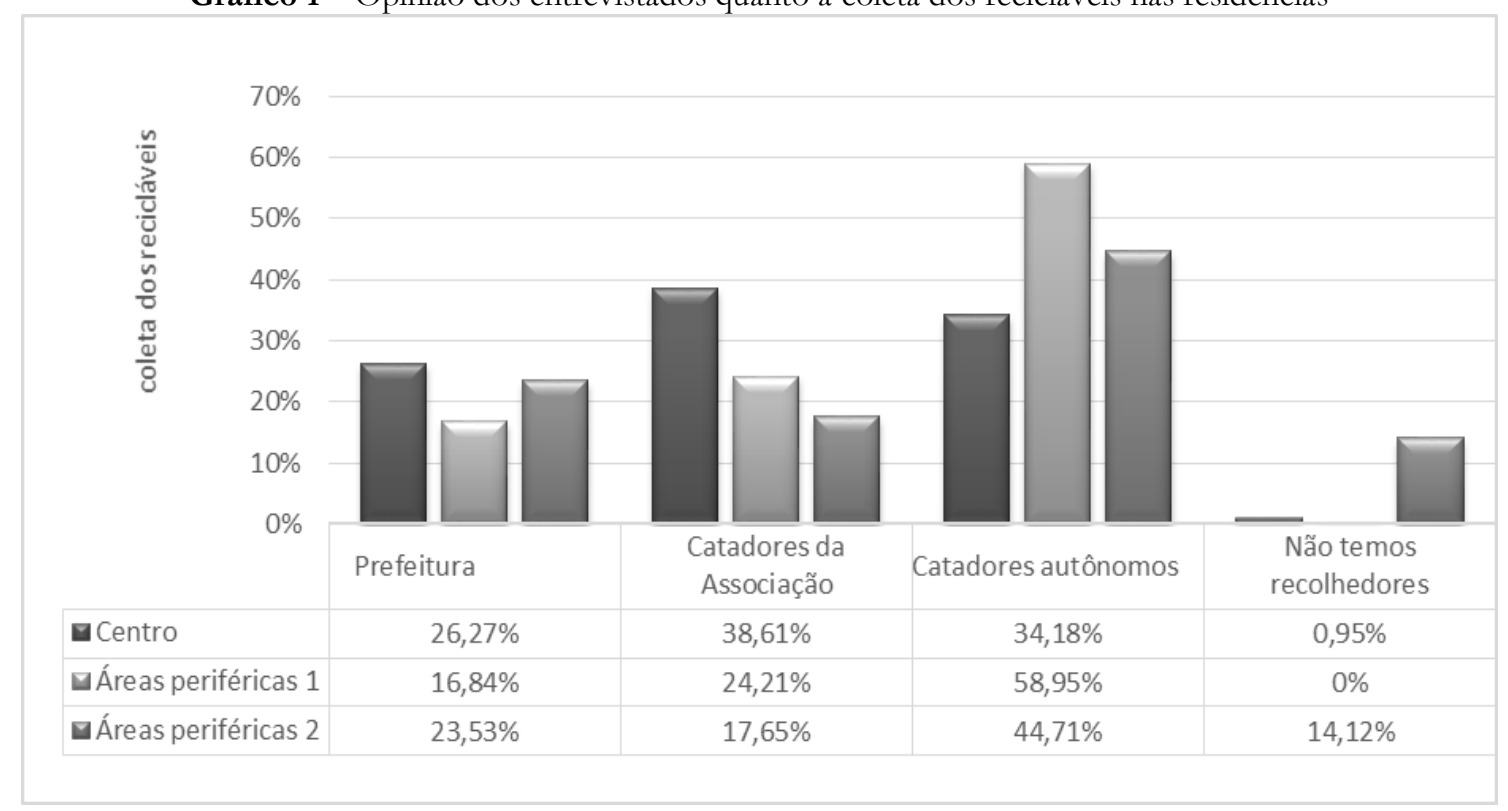

Fonte: GALDINO, S. J. (2014).

$\mathrm{Na}$ área central do município, $38,61 \%$ dos moradores relataram que, a coleta dos materiais recicláveis é realizada por catadores organizados em associação. Isso está relacionado à maior preocupação do poder público quanto à organização, estética e limpeza de vias centrais, onde se concentram as atividades de comércios e serviços.

Outro dado importante diz respeito à inexistência de recolhedores em alguns domićlios das áreas consideradas de baixa renda (áreas periféricas 2), ou seja, 14,12\% dos moradores relataram que não há coleta. Tal fato se explica pelas dificuldades de acesso em algumas vias (terrenos muito íngremes), grande quantidade de cachorros soltos, menor quantidade de recicláveis e ausência de veículo adequado para coleta nestes locais.

Dentro deste contexto, o planejamento da coleta e transporte deve ser feito levando em consideração a capacidade de armazenamento dos resíduos nos domićlios, características, quantidades geradas e, quando necessário, redimensionamento de itinerários de coleta, da frequência, do número de veículos e da mão de obra a ser disponibilizada. 
| Percepção ambiental quanto ao gerenciamento de resíduos sólidos domiciliares: estudo de caso da cidade de Mamborê, Paraná|

\section{| Silvana de Jesus Galdino | Maila Mirian Ferreira Carvalho |}

No planejamento da coleta convencional dos resíduos sólidos domiciliares deve-se levar em consideração as áreas de difícil acesso (vielas estreitas, terrenos íngremes). Desta forma, recomenda-se utilizar veículos especiais, de pequena largura, boa capacidade de manobra, evitando, assim, acúmulo de resíduos nas residências.

Com base no Gráfico 2, que aborda a qualidade dos serviços de coleta dos materiais recicláveis no município, 67,09\% dos moradores entrevistados da área central consideram a coleta como boa, 6,01\% como ótima, 23,73\% regular, 3,16\% ruim. Entretanto, 1,18\% dos moradores entrevistados nas áreas periféricas (2), áreas mais carentes, disseram que a coleta de recicláveis é péssima.

Gráfico 2 - Opinião dos entrevistados quanto ao manejo dos materiais recicláveis residenciais

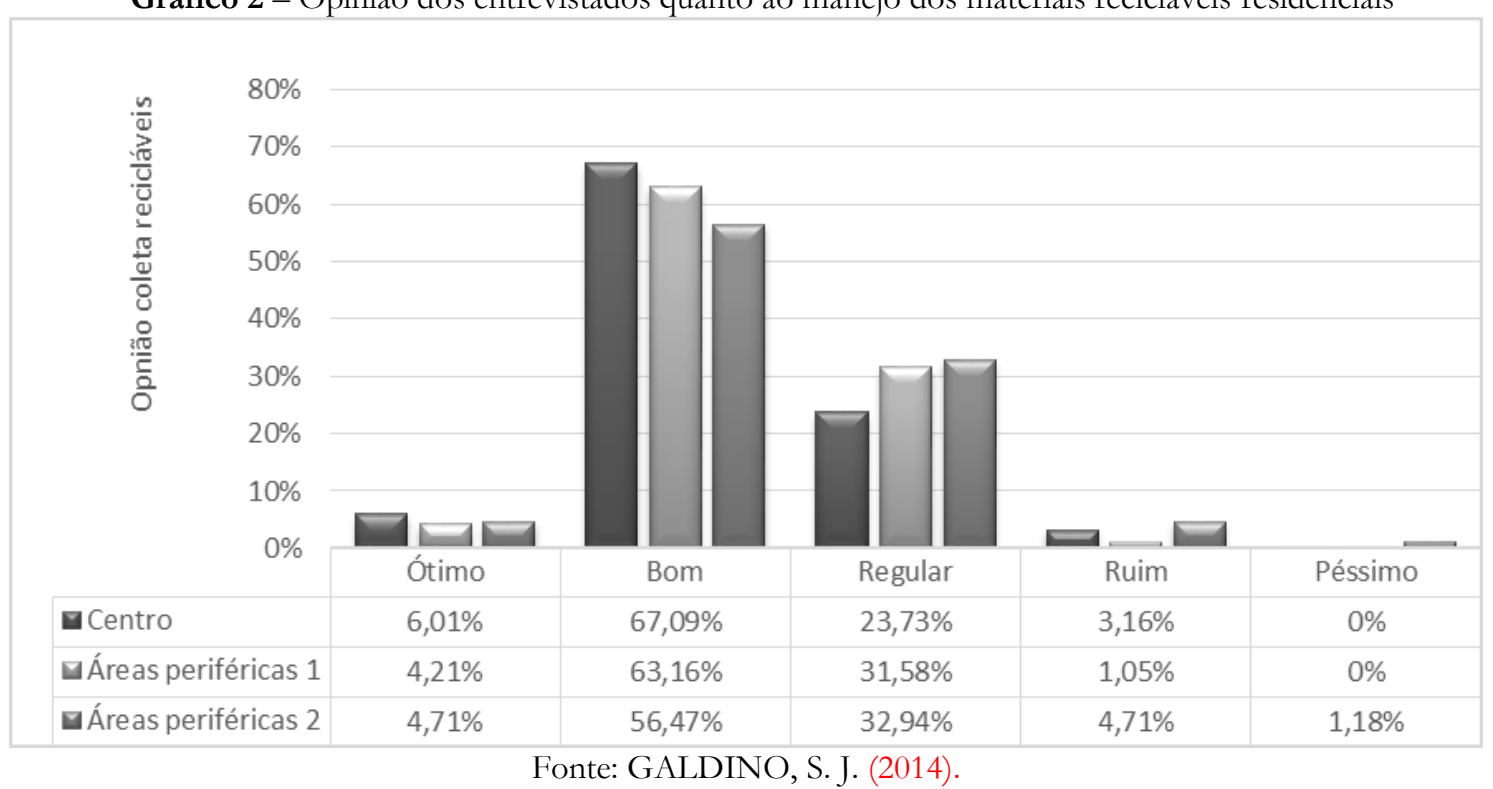

Mesmo existindo várias deficiências no manejo dos resíduos sólidos domiciliares do município, a maioria dos moradores considera a coleta de materiais recicláveis como boa ou regular. Todavia, o poder público precisa investir mais em campanhas de educação ambiental, infraestrutura e sensibilização dos moradores quanto à separação e disposição dos resíduos para coleta.

Antes da coleta convencional dos resíduos sólidos domiciliares ou coleta dos recicláveis realizada por catadores, 55,99\% dos entrevistados da área central relataram que disponibilizam os resíduos em suportes adequados, 30,28\% na calçada e, os demais, sobre muros, árvores ou cercas. Nas áreas periféricas (2), 48,68\% dos moradores disponibilizam os resíduos para coleta na calçada, $43,42 \%$ em suporte adequado e outros sobre muros e pendurados em árvores ou cercas.

A disposição dos resíduos em suportes adequados facilita o trabalho de coleta, evita o rompimento das embalagens e espalhamento dos resíduos pela vizinhança, ao contrário 
| Percepção ambiental quanto ao gerenciamento de resíduos sólidos domiciliares: estudo de caso da cidade de Mamborê, Paraná|

| Silvana de Jesus Galdino | Maila Mirian Ferreira Carvalho|

do que foi constatado em residências onde os resíduos são colocados sobre muros e pendurados em árvores. Em alguns dos casos, a disposição dos resíduos em muros e calçadas é necessário devido à presença de animais soltos na rua, como foi relatado anteriormente.

A respeito da opinião quanto ao trabalho desempenhado pelos catadores de materiais recicláveis: nas áreas periféricas 2, 92\% disseram ser importante; nas áreas periféricas 1, 97\% disseram ser importante o trabalho realizado pelos catadores de materiais recicláveis e, na área central, 95\% dos entrevistados declararam que o trabalho desempenhado pelos catadores de materiais recicláveis é importante. Os demais entrevistados foram neutros ou consideraram o trabalho sem importância ou pouco importante.

Durante entrevista $85 \%$ dos moradores da área central disseram ter conhecimento sobre a coleta dos materiais recicláveis, e 15\% declararam não ter conhecimento. Nas áreas periféricas 1, aproximadamente $75 \%$ dos entrevistados disseram ter conhecimento da coleta seletiva, enquanto $25 \%$ disseram não ter conhecimento.

Nas áreas periféricas 2, consideradas mais carentes do município, 70\% destacaram ter conhecimento a respeito da existência da coleta seletiva, enquanto 30\% disseram não ter conhecimento desse serviço prestado. Fato este que se justifica diante das dificuldades de acesso e transporte dos materiais nessas áreas, uma vez que, trata-se de terrenos mais íngremes, em muitos dos casos com vias deterioradas e estreitas, próximas às encostas.

Nesse sentido, conforme destaca Laureano (2009), a educação ambiental não se preocupa apenas com a aquisição de conhecimento, mas também, fundamentalmente, visa possibilitar um processo de mudança de comportamento e aquisição de novos valores e conceitos convergentes às necessidades do mundo atual, com as inter-relações e interdependências que se estabelecem entre o ambiente social, cultural, econômico, psicológico e humano.

Considerando o importante papel que a população tem no processo de gerenciamento dos resíduos sólidos domiciliares, foi perguntado aos informantes qual o tipo de recipiente costuma utilizar diariamente para acondicionar os resíduos.

De maneira geral, quanto aos meios utilizados para armazenar os resíduos sólidos (cascas de ovos, restos de comida, cascas de frutas, papel, vidro, plásticos etc..); 12,85\% do total de entrevistados relataram que armazenam em latões, latas ou baldes; $22,80 \%$ do total armazenam em caixas de papelão ou similares; 43,44\% armazenam em sacos de lixo apropriados; 20,22\% armazenam em sacolinhas reaproveitadas de compras e apenas 0,66\% separam a matéria orgânica e utilizam como adubo (Gráfico 3). 
| Percepção ambiental quanto ao gerenciamento de resíduos sólidos domiciliares: estudo de caso da cidade de Mamborê, Paraná|

| Silvana de Jesus Galdino | Maila Mirian Ferreira Carvalho|

Gráfico 3 - Recipientes utilizados para armazenar os resíduos gerados nas residências

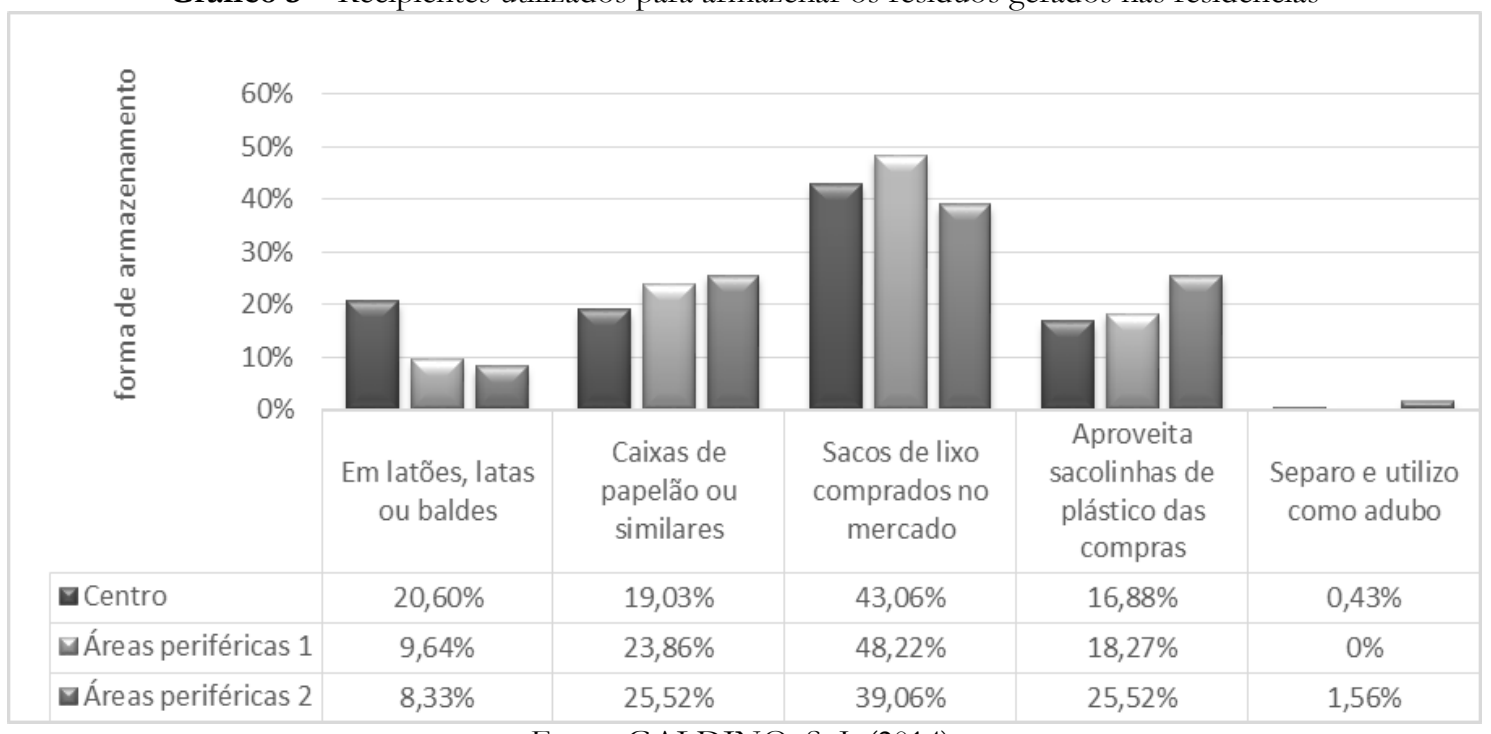

Fonte: GALDINO, S. J. (2014).

É possível observar que, o armazenamento em sacolinhas plásticas das compras, latões, latas e tambores sem tampa, são considerados pontos negativos que podem criar condições ideais para o desenvolvimento de agentes patogênicos responsáveis pela transmissão de doenças. Portanto, micro-organismos podem estar presentes em lenços umedecidos, fraldas descartáveis, fezes de animais domésticos, absorventes higiênicos e alimentos perecíveis.

A segregação diretamente na fonte geradora evita que os resíduos se contaminem, contribui para aumentar a quantidade e qualidade dos resíduos recicláveis e orgânicos, valorização no mercado de recicláveis, além de facilitar o processo de transporte, armazenamento e destinação final (ALBUQUERQUE, 2008; JUNIOR, 2003; ROCHA, 2009).

Quanto à maneira de acondicionar os materiais recicláveis para a coleta (Gráfico 4), $44,7 \%$ dos entrevistados da área central utilizam recipientes diferentes para cada tipo de resíduos, 32,7\% misturam tudo no mesmo recipiente e 22,6\% misturam tudo com o "lixo" normal, queimam ou não se preocupam com isso e, até mesmo, adotam outras maneiras de acondicionamento.

Cardoso (2004) destaca que em muitas cidades ainda são usados latões sem tampa e pesados. O emprego desse sistema, embora traga economia aos usuários em virtude do recipiente ser retornável, resulta em consideráveis atrasos nos procedimentos de coleta.

Existem no mercado sacos plásticos específicos para acondicionamento dos resíduos recicláveis e orgânicos, entretanto, a reutilização de sacolas plásticas provenientes das compras em estabelecimentos comerciais ainda é bastante comum, principalmente nos domicílios. Todavia, resíduos que possam causar algum tipo de acidente ou contaminação 
| Percepção ambiental quanto ao gerenciamento de resíduos sólidos domiciliares: estudo de caso da cidade de Mamborê, Paraná|

| Silvana de Jesus Galdino | Maila Mirian Ferreira Carvalho|

ao coletor devem ser devidamente embalados, tais como, seringas, vidro, lâmpadas, latas abertas, agulhas e pregos.

No Gráfico 4 percebe-se as diferentes formas de acondicionamento dos materiais recicláveis pelos moradores nas três áreas consideradas para estudo: área central; áreas periféricas 1 e áreas periféricas 2, respectivamente.

Gráfico 4 - Forma de acondicionamento dos materiais recicláveis gerados nas residências

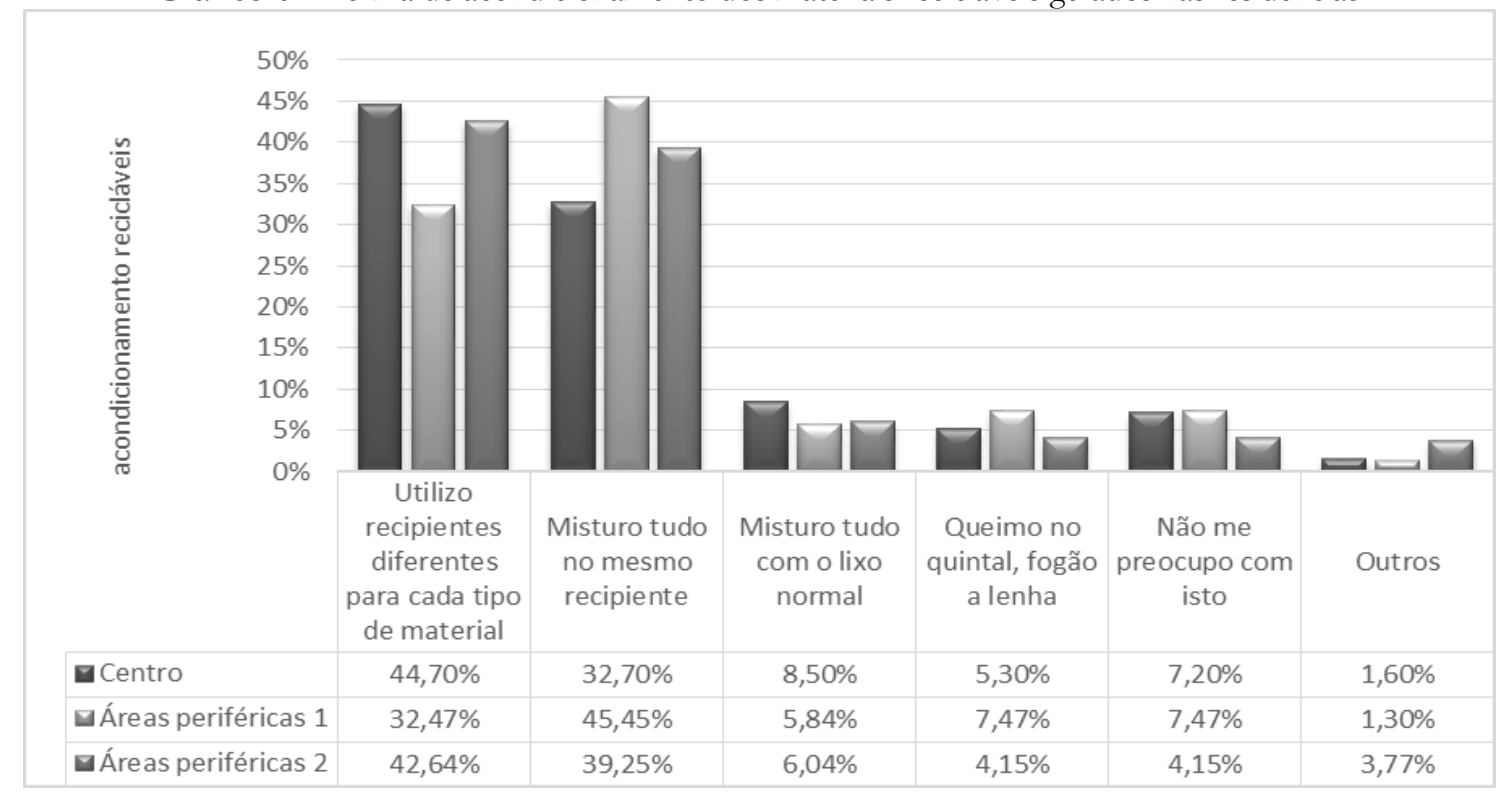

Fonte: GALDINO, S. J. (2014).

Quanto ao descarte de recipientes de vidro, louças quebradas ou materiais pontiagudos, 40,33\% do total dos entrevistados relataram que enrolam em jornal para proteger os catadores de materiais recicláveis, enquanto que 57,16\% não enrolam em papel, misturando tudo com o material reciclado e 7,5\% adotam outras alternativas, tais como caixas de papelão e embalagens.

Em relação aos costumes de descartes de resíduos perigosos, como pilhas, baterias e lâmpadas florescentes utilizadas no domicílio, 46,52\% separam para fazer o descarte adequado, 11,18\% responderam que misturam tudo com os resíduos destinados à coleta convencional, 32,86\% colocam tudo junto com o material reciclado, 7,95\% declararam não se preocupar com essa questão e 1,49\% adotam outras alternativas, como devolver ao local de compra do produto. Isso está relacionado à deficiência quanto à divulgação dos locais para a entrega dos materiais potencialmente perigosos e conscientização quanto aos riscos ambientais e sociais.

De acordo com o Decreto Federal n ${ }^{\circ} 7.405 / 2010$, em seu art. $6^{\circ}$, os consumidores são obrigados, quando da existência de coleta seletiva, ou sistema de logística reversa, acondicionar, separar e disponibilizar adequadamente os resíduos para a coleta ou 
| Percepção ambiental quanto ao gerenciamento de resíduos sólidos domiciliares: estudo de caso da cidade de Mamborê, Paraná|

| Silvana de Jesus Galdino | Maila Mirian Ferreira Carvalho|

devolução. A maneira como se processa os serviços de coleta e transporte dos resíduos sólidos dependerá das condições de separação, armazenamento e acondicionamento dos mesmos, bem como, da disposição dos recipientes em dias e horários estabelecidos.

Em relação à opinião sobre a destinação final dos resíduos sólidos gerados no domicílio, 97,65\% responderam lixão ou aterro sanitário, 1,10\% incineração, tendo em vista que a segunda alternativa não é utilizada nos gerenciamentos dos resíduos gerados nos domićlios. Apenas 0,35\% apontaram as usinas de triagem e reciclagem como alternativa para gerenciamento dos materiais recicláveis.

Quanto aos problemas causados pela disposição irregular dos resíduos sólidos urbanos gerados nos domicílios de Mamborê-PR, foram apontadas diferentes respostas como aparecimento de pragas, poluição da água, poluição do ar, aparecimento do mosquito causador da dengue, desmatamento, queimadas e poluição visual e olfativa.

Diante dos problemas apontados pelos moradores, um dos dados mais alarmantes é a preocupação quanto aos focos do mosquito causador da dengue. $\mathrm{Na}$ área central (Gráfico 5), 42,86\% dos indivíduos destacam a dengue como problema causado pela disposição irregular dos resíduos sólidos. Nas demais áreas onde foram aplicados os questionários, a preocupação em relação à proliferação do mosquito transmissor da dengue também é visível, 45,28\% dos entrevistados nas áreas periféricas 1 e 34,72\% dos entrevistados nas áreas periféricas 2 .

Gráfico 5 - Os problemas causados pela disposição irregular dos resíduos domiciliares

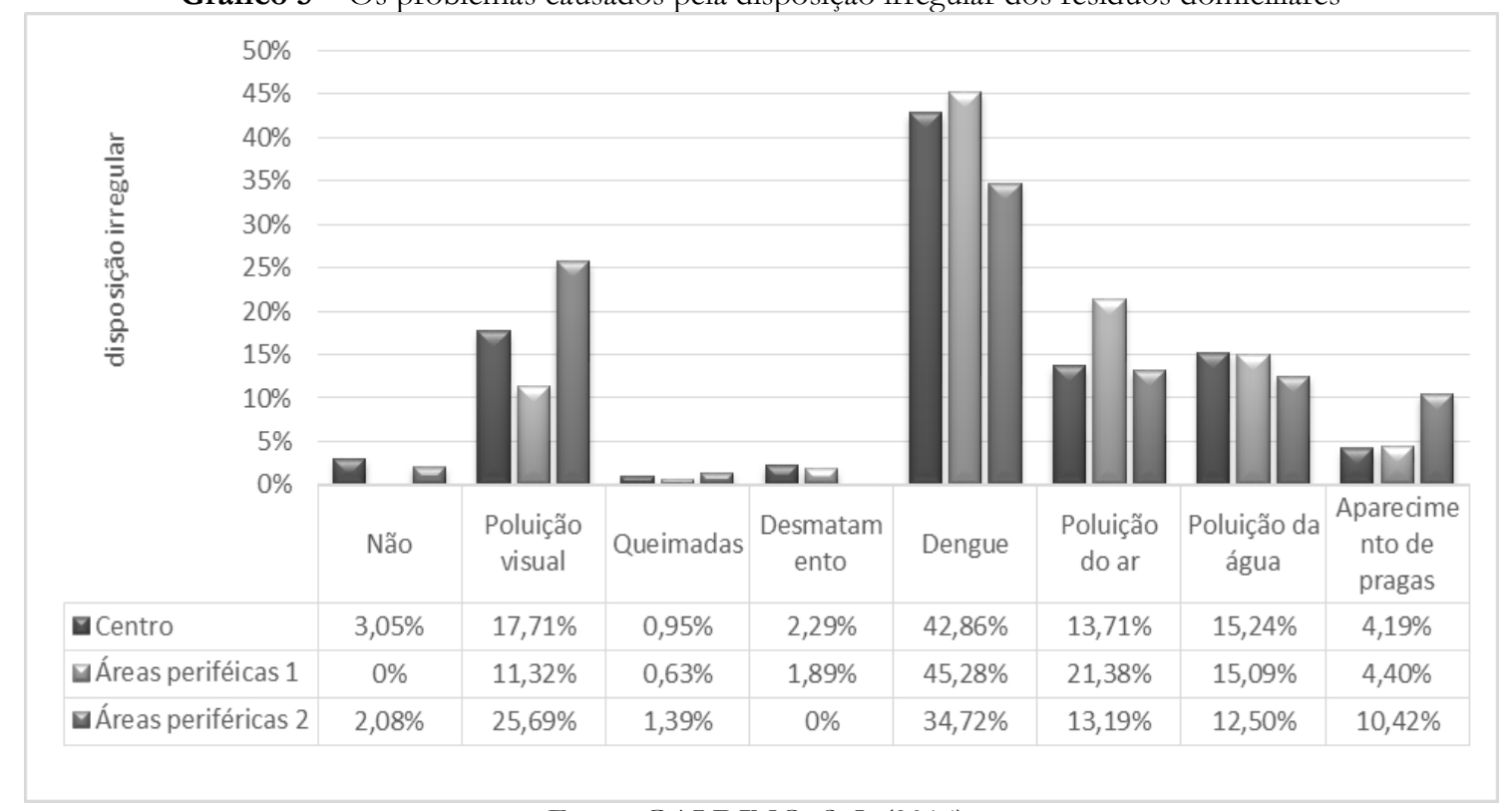

Fonte: GALDINO, S. J. (2014). 
| Percepção ambiental quanto ao gerenciamento de resíduos sólidos domiciliares: estudo de caso da cidade de Mamborê, Paraná|

| Silvana de Jesus Galdino | Maila Mirian Ferreira Carvalho|

O ato de dispor os resíduos de forma irregular também tem sido apontado por 16\% dos moradores como geradores de poluição do ar, 14\% como causadores de poluição da água, 18\% como causadores de poluição visual, 9,29\% relataram que a disposição irregular dos resíduos contribui para o aparecimento de pragas, desmatamento e queimadas e 1,71\% dos informantes não souberam ou não consideram a disposição irregular de resíduos como um problema.

Isso demonstra que, os moradores têm conhecimento prévio da realidade na qual estão inseridos, dos problemas causados pela disposição irregular dos resíduos gerados nas residências, entretanto, observa-se que, o conhecimento dos problemas nem sempre gera mudanças de atitudes ou hábitos. Portanto, faz-se necessário um conjunto de ações articuladas entre sociedade em geral e o poder público, a fim de implementar programas de educação e sensibilização ambiental coletiva.

$\mathrm{Na}$ opinião dos entrevistados das três áreas analisadas, as responsabilidades quanto à destinação final dos resíduos sólidos gerados nos domicílios seria da prefeitura $(36,30 \%$ da opinião), 24,10\% responsabilizam cada morador, 19,23\% responsabilizam o serviço de limpeza pública do município, $7,34 \%$ das escolas, $6,75 \%$ da sociedade como um todo e 6,26\% destacam que, os problemas causados pela disposição irregular dos resíduos, seriam de responsabilidade dos catadores de materiais recicláveis.

Em relação aos hábitos de reutilizarem algum tipo de material reciclável, 15,98\% dos entrevistados responderam que não reutilizam nenhum tipo de material ou objeto, $21,37 \%$ reutilizam vidros, $28,02 \%$ reutilizam recipientes em alumínio, 30,15\% reutilizam sacolinhas reaproveitadas das compras de mercado, $4,48 \%$ reutilizam caixas.

Nos Gráficos 6, 7 e 8 percebe-se a opinião dos moradores entrevistados quanto ao nível de concordância sobre os problemas econômicos, sociais e ambientais decorrente das falhas ou ausência de gerenciamento adequado dos resíduos sólidos gerados no espaço urbano. Para tal foi utilizada a seguinte escala: Concordo totalmente (CT), Concordo (C), Não concordo, nem discordo (I), Discordo parcialmente (DP) e Discordo totalmente (DT).

O que fazer com os resíduos sólidos gerados nos domićlíos pode ser considerado um problema de ordem ambiental, social e econômico. Diante disso, no Gráfico 6, percebe-se o nível de concordância quanto aos problemas econômicos decorrentes da geração de resíduos nos domicílios de Mamborê-PR, sendo que 17,41\% dos entrevistados da área central, 41,05\% das áreas periféricas 1 e 27,06\% das áreas periféricas 2 relataram que concordam totalmente com tal afirmação. Os que concordam são 57,91\%, 43,16\% e 
| Percepção ambiental quanto ao gerenciamento de resíduos sólidos domiciliares: estudo de caso da cidade de Mamborê, Paraná|

| Silvana de Jesus Galdino | Maila Mirian Ferreira Carvalho|

36,47 dos entrevistados dessas áreas, respectivamente. Ambas as porcentagens de cada item são representadas nos gráficos 6,7 e 8.

Gráfico 6 - Concordância quanto aos problemas econômicos dos resíduos domiciliares

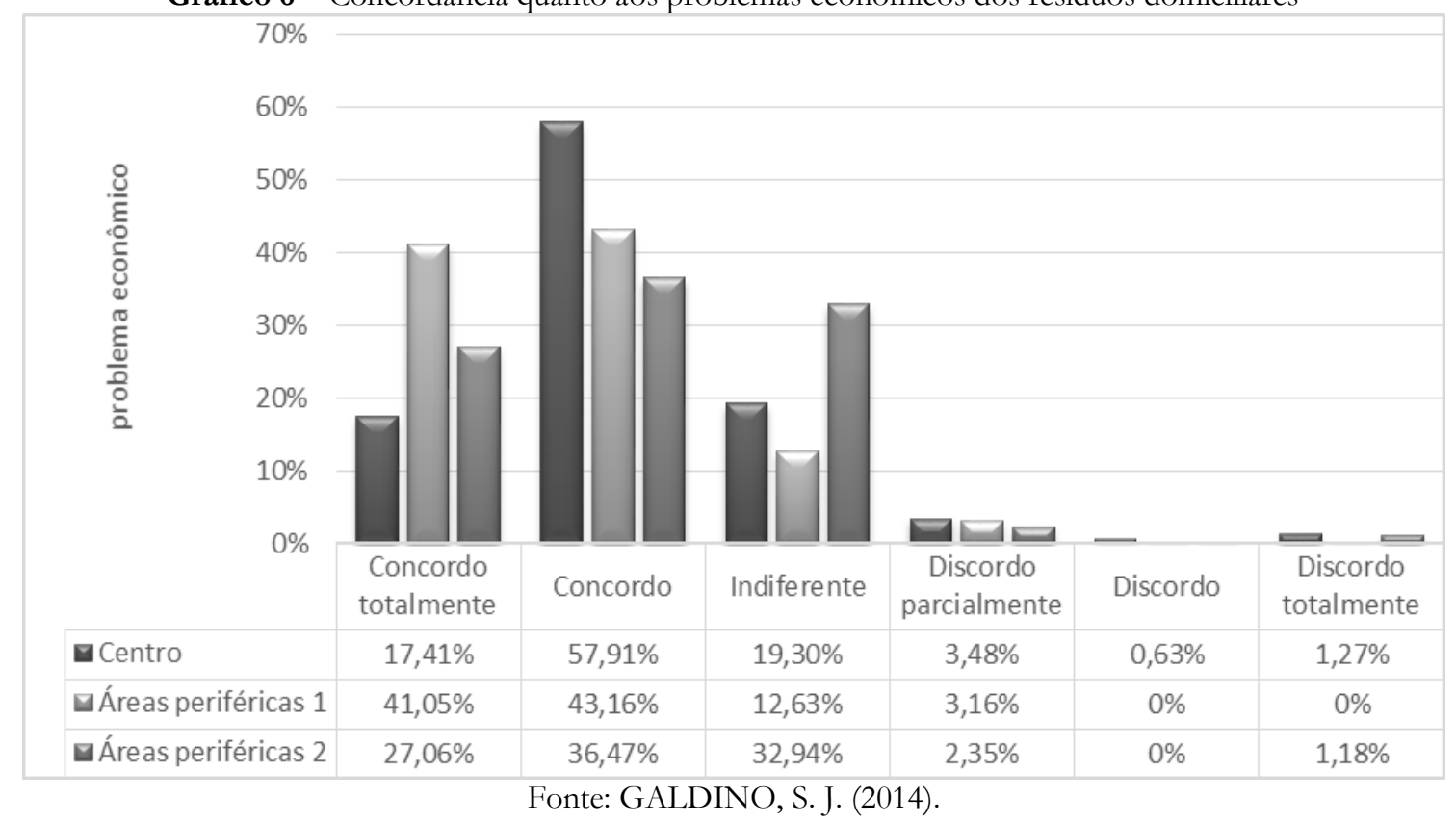

Quanto ao valor social e econômico, a reciclagem tem se configurado como alternativa para a contenção da exploração dos recursos naturais, diminuição na contaminação do ar, solo, água e melhorias na qualidade de vida do ser humano, reduz os desperdícios e gastos com limpeza urbana, além de gerar emprego e renda nas associações e cooperativas de catadores de materiais recicláveis.

Cortez (2002) salienta que a reciclagem não deve ser vista como a principal solução para o destino dos resíduos, pois é uma atividade econômica que deve ser encarada como um elemento dentro de um conjunto de soluções integradas no gerenciamento dos resíduos sólidos, levando em consideração que nem todos os materiais são técnica ou economicamente recicláveis.

No Gráfico 7 sobre o nível de concordância quanto a geração de resíduos sólidos domiciliares ser considerado um problema social, 19,94\% dos entrevistados da área central e 38,95\% das áreas periféricas 1 e 22,35\% das áreas periféricas 2 declararam que concordam totalmente com tal afirmação. Já os que apenas concordam são 55,70\%, $45,26 \%$ e 45,88\% das respectivas áreas. Os que discordam totalmente de tal afirmação são $0,32 \%$ e $0 \%$ das respectivas áreas. 
| Percepção ambiental quanto ao gerenciamento de resíduos sólidos domiciliares: estudo de caso da cidade de Mamborê, Paraná|

| Silvana de Jesus Galdino | Maila Mirian Ferreira Carvalho|

Gráfico 7 - Concordância quanto ao problema social da geração de resíduos domiciliares

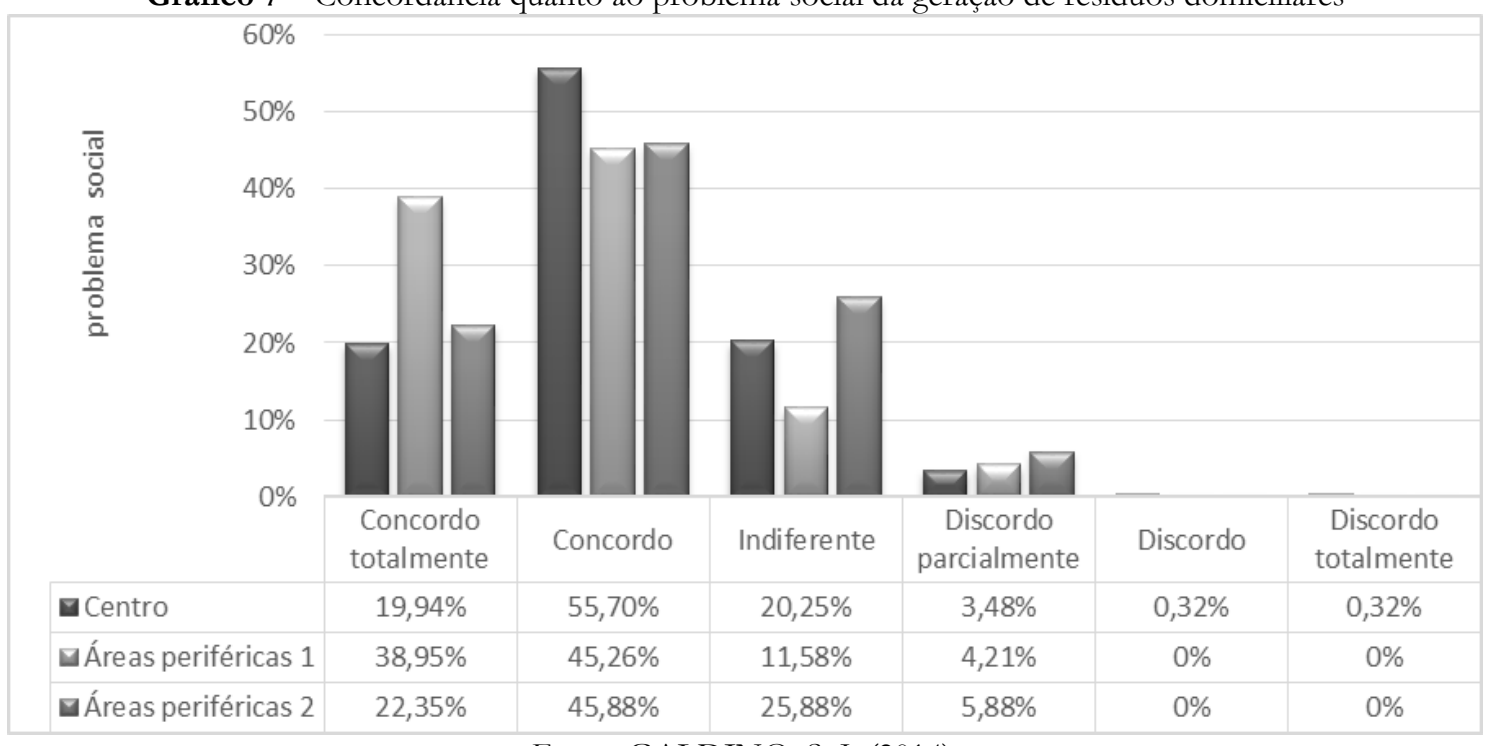

Fonte: GALDINO, S. J. (2014).

No que diz respeito à geração de resíduos sólidos domiciliares como problema ambiental (Gráfico 8), 31,33\% dos entrevistados da área central, 44,21\% das áreas periféricas 1 e 23,53\% das áreas periféricas 2 concordam totalmente com esta afirmativa, enquanto 46,20\%,42,11\% e 38,82, receptivamente, apenas concordam. Os que discordam totalmente foram 1,27\% dos entrevistados da área central, $0 \%$ das áreas periféricas $1 \mathrm{e}$ $1,18 \%$ das áreas periféricas 2.

Gráfico 8 - Concordância quanto aos problemas ambientais decorrentes dos resíduos domiciliares

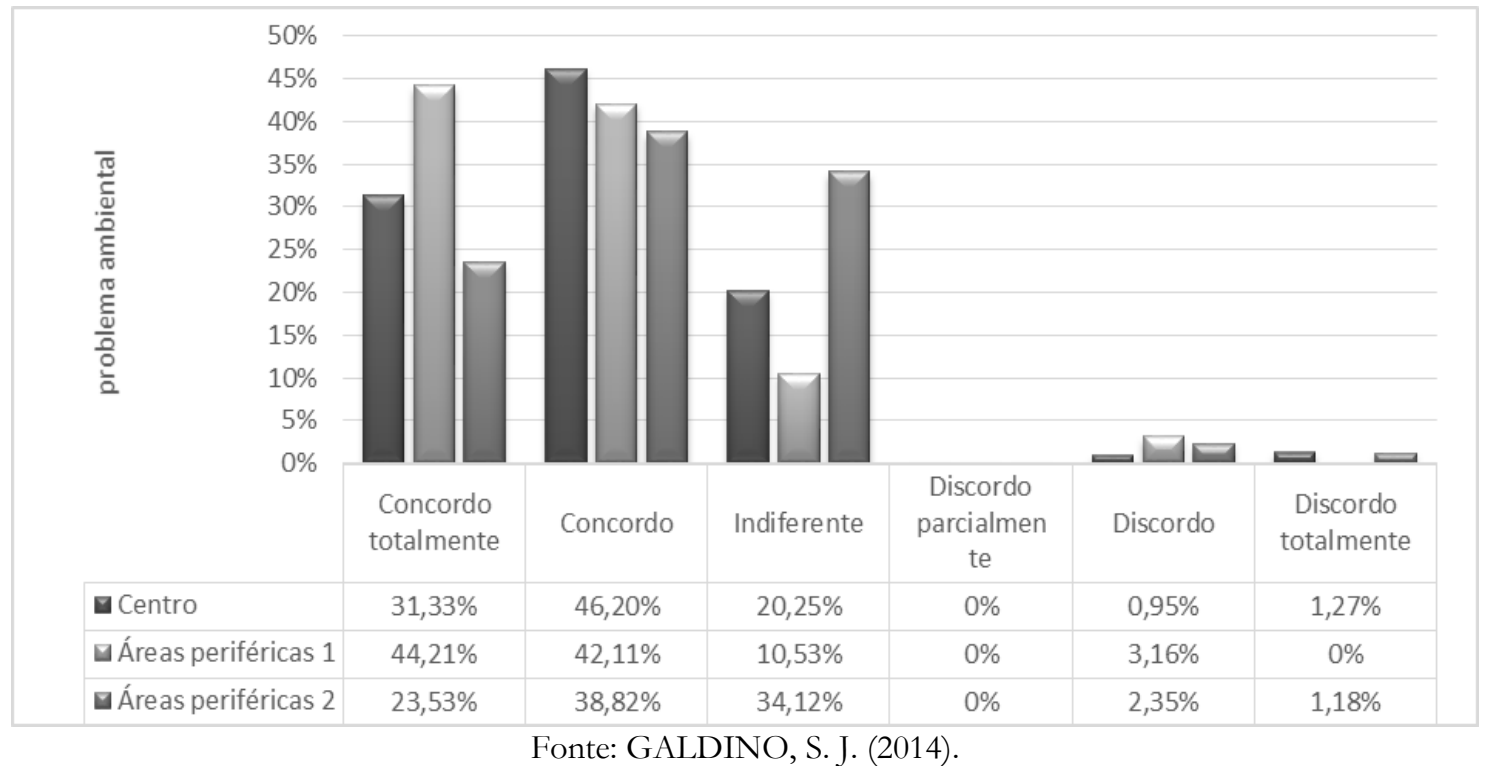

Em relação à destinação final dos resíduos orgânicos e recicláveis gerados nos domicílios do município, em média 85\% dos entrevistados considera como regular a bom. 
| Percepção ambiental quanto ao gerenciamento de resíduos sólidos domiciliares: estudo de caso da cidade de Mamborê, Paraná|

| Silvana de Jesus Galdino | Maila Mirian Ferreira Carvalho|

Resultados estes que apontam para a necessidade de maiores investimentos em programas de educação ambiental e conscientização da população. Diante desta questão, conclui-se que, uma parcela significativa dos entrevistados não tem conhecimento das reais condições de disposição final dos materiais recicláveis gerados no município.

De acordo com Dias e Moraes (2008), o problema quanto à destinação final ambientalmente adequada dos resíduos se agravou nos últimos anos com o advento da chamada "cultura dos descartáveis", ou seja, preferência por embalagens descartáveis em função da facilidade e comodidade aos usuários. Com o advento da chamada "cultura dos descartáveis", os lixões e aterros sanitários começaram a receber um volume muito alto de embalagens, resíduos potencialmente recicláveis com resíduos perigosos, tornando insuficiente o serviço prestado pelo poder público.

Levantamento realizado pela Associação Brasileira de Empresas de Limpeza Pública e Resíduos Especiais (ABRELPE, 2016) constatou que, a maioria dos municípios brasileiros não se adequou à Lei 12.305 da Política Nacional de Resíduos Sólidos, principalmente no que diz respeito à erradicação dos lixões a céu aberto e construção de aterros sanitários. Sendo assim, o prazo foi prorrogado até final de 2020, e o não cumprimento poderá acarretar em multas por crime ambiental e, até mesmo, cortes de verbas do governo federal.

No que diz respeito às alternativas para melhorar o manejo dos resíduos sólidos domiciliares, aproximadamente 26,4\% dos entrevistados das três áreas consideraram a educação ambiental como uma das alternativas, 23,3\% em investimento em coleta, 12,6\% investimento em reciclagem, 21,3\% responderam sobre a necessidade de investimentos em infraestrutura, organização e planejamento do processo de gerenciamento dos resíduos e 16,4\% não opinaram ou consideram o manejo dos resíduos como bom, sem necessidade de mudanças.

Durante pergunta relacionada à disponibilidade para participar de cursos sobre armazenamento, acondicionamento e disposição correta dos resíduos para a coleta, 55,94\% disseram que não gostariam de participar, $19,85 \%$ se comprometeriam a participar e $24,21 \%$ não opinaram ou ficaram indecisos. Todavia a preocupação em diminuir a quantidade de resíduos gerados nos domicílios foi de 75,22\%, os demais não teriam essa preocupação ou ficaram indecisos.

Tais informações apontam para a falta de interesse por parte da população consultada quanto à participação em programas de educação ambiental. Isso pode estar relacionado à ausência de credibilidade no poder público, a necessidade de mudanças de hábitos e costumes, falta de tempo ou conhecimento sobre o assunto. 
| Percepção ambiental quanto ao gerenciamento de resíduos sólidos domiciliares: estudo de caso da cidade de Mamborê, Paraná|

| Silvana de Jesus Galdino | Maila Mirian Ferreira Carvalho|

Diante de tal problemática, a ordem de prioridade para a gestão dos resíduos sólidos, proposta pela PNRS (Política Nacional de Resíduos Sólidos), Lei 12.305/2010, é a não geração, redução, reutilização, reciclagem, tratamentos dos resíduos sólidos e disposição ambientalmente adequada dos rejeitos.

De acordo com as Diretrizes da PNRS, Lei 12.305/2010 que dispõe sobre a destinação final ambientalmente adequada dos resíduos, os municípios terão que eliminar as irregularidades do trabalho desempenhado pelos catadores de materiais recicláveis, implantar sistemas de coleta seletiva, centrais de triagem e comercialização, coleta diferenciada dos resíduos orgânicos para compostagem.

Diante das novas exigências a respeito do gerenciamento dos resíduos sólidos urbanos, a Secretaria de Agricultura, Meio Ambiente e Desenvolvimento Econômico de Mamborê-PR apontou algumas alternativas, como adotar soluções consorciadas intermunicipais para destinação final ambientalmente correta dos resíduos, bem como, a regularização da coleta seletiva e implantação de Central de Triagem e Compostagem de Resíduos Sólidos (CTCRS).

Dentre as alternativas apontadas está à implantação de um sistema de compostagem para resíduos sólidos orgânicos, em articulação com os agentes econômicos e sociais, forma de utilização do composto produzido de acordo com o plano intermunicipal de gestão integrada dos RSU. Para tanto, a prefeitura pretende iniciar projeto com objetivo de implantar um Centro de Triagem e Compostagem de Resíduos Sólidos (CTCRS), ambos funcionando de maneira conjunta.

De acordo com o órgão gestor, há necessidade de elaborar um plano para a capacitação permanente das famílias que sobrevivem da coleta seletiva, estimulando o retorno à escola, pois a educação e a capacitação de mão de obra serão eficientes na busca da emancipação social e financeira dessas famílias.

Durante levantamento de dados junto ao órgão gestor, foi constatada a necessidade de regulamentação da coleta seletiva através de projeto de Lei Municipal que contemple as especificidades da coleta dos recicláveis, definir como será explorada a coleta seletiva e fortalecer o trabalho dos catadores da associação e autônomos.

Segundo o Plano Diretor Municipal (2014), a Lei Municipal virá de encontro com as necessidades de mudança de atitude com relação à separação dos materiais, tornando obrigatório o ato da separação dos recicláveis, dentre outras exigências para o manejo do "lixo". Sensibilizar/educar a população sobre a necessidade de separação dos recicláveis, por meio de lei, com a previsão de aplicação de multa para quem não reciclar/separar o "lixo" corretamente. 
| Percepção ambiental quanto ao gerenciamento de resíduos sólidos domiciliares: estudo de caso da cidade de Mamborê, Paraná|

| Silvana de Jesus Galdino | Maila Mirian Ferreira Carvalho|

Quanto aos programas de educação ambiental e conscientização da população, a Secretaria de Meio Ambiente pretende investir mais em projetos juntamente com as escolas e comunidades, alertando quanto aos problemas ocasionados pela disposição irregular dos resíduos. Para tanto, envolver a comunidade em geral em projetos de reaproveitamento de materiais recicláveis, uso consciente dos produtos, reaproveitamento da matéria orgânica no processo de compostagem, bem como a utilização do composto.

\section{CONSIDERAÇÕES FINAIS}

No presente trabalho evidenciou-se que a cidade de Mamborê-PR possui várias deficiências na gestão e gerenciamentos dos resíduos sólidos provenientes da coleta convencional e seletiva. Como fator agravante, neste contexto, tem-se a dificuldade em desenvolver ações de educação ambiental voltadas para a separação dos resíduos domiciliares diretamente na fonte geradora, pois, mesmo tendo conhecimentos dos problemas decorrentes do gerenciamento inadequado dos resíduos, 55,4\% dos informantes não têm o hábito de separar os resíduos para a coleta, acondicionando-os em mesmo recipiente, dificultando assim o trabalho realizado por garis/coletores e catadores de materiais recicláveis.

Diante do diagnóstico da atual situação de gerenciamento e gestão dos resíduos sólidos domiciliares do município de Mamborê-PR ficou evidente a necessidade de implantação de Plano de Gerenciamento Integrado dos Resíduos, de maneira a contemplar os aspectos econômicos, sociais e ambientais.

\section{REFERÊNCIAS}

ABRELPE - Associação Brasileira de Empresas de Limpeza Pública e Resíduos Especiais. Panorama dos Resíduos Sólidos no Brasil. São Paulo: ABRELPE, 2016.

ASSOCIAÇÃO BRASILEIRA DE NORMAS TÉCNICAS - ABNT. NBR 10.004/2004 -Resíduos Sólidos - Classificação. São Paulo: ABNT, 2004.

BIDONE, F. R. A.; POVINELLI, J. Conceitos básicos de resíduos sólidos. São Carlos, SP: EESC/SP, 1999.

BRASIL. Decreto $n^{\circ}$ 7.405, de 23 de dezembro de 2010. Institui o Programa PróCatador. Brasília: Comitê Interministerial para Inclusão Social e Econômica dos Catadores de Materiais Reutilizáveis e Recicláveis, 2010. 
| Percepção ambiental quanto ao gerenciamento de resíduos sólidos domiciliares: estudo de caso da cidade de Mamborê, Paraná|

| Silvana de Jesus Galdino | Maila Mirian Ferreira Carvalho|

BRASIL. Lei Federal no 12.305, de 12 agosto de 2010. Política Nacional de Resíduos

Sólidos. Brasília: $2010 . \quad$ DMA, em:

< http://www.camara.gov.br/sileg/integras/501911.pdf> . Acesso em: 15 jan. 2019.

CARDOSO, O. Gestão dos Resíduos Sólidos Urbanos do município de Campo Mourão/PR. 2004. Dissertação (Mestrado em Geografia) - Universidade Estadual de Maringá, Maringá, 2004.

CORTEZ, A. T. C. Coleta seletiva e reciclagem de resíduos sólidos urbanos. In: CAMPOS, J. O.; BRAGA, R.; CARVALHO, P. F. (Org.). Manejo de resíduos sólidos: pressuposto para a gestão ambiental. Rio Claro: Laboratório de Planejamento Municipal - DEPLAN; IGCE/UNESP, 2002. p. 99-109.

D`ALMEIDA, M. L. O.; VILHENA, A. Lixo municipal: manual de gerenciamento integrado. 2. ed. São Paulo: CEMPRE, 2000.

DIAS, J. A; MORAES, A. M. F. Os Resíduos sólidos e a responsabilidade ambiental pós-consumo. 2. ed. Marília: PRSP/MPF, 2008.

IBGE - Instituto Brasileiro de Geografia e Estatística. Contagem Populacional. 2010. Disponível em: < $\underline{\text { http://geoftp.ibge.gov.br> }}$. Acesso em: 18 fev. 2019.

IPARDES. Instituto Paranaense de Desenvolvimento Econômico e Social. 2011. Disponível em: < http://www.ipardes.gov.br>. Acesso em: 10 fev. 2019.

LAURIANO, W. E. Contribuição para o programa de gerenciamento de resíduos sólidos e melhoria da qualidade socioambiental na instituição de ensino superior Fecilcam, Campo Mourão - Pr. In: ENCONTRO DE PRODUÇÃO CIENTÍFICA E TECNOLÓGICA, 2009, Campo Mourão. Anais... Campo Mourão-PR: FECILCAM, 2009.

MONTEIRO, J. H. P. [et al.]. Manual de Gerenciamento Integrado de Resíduos Sólidos. Coordenação técnica Victor Zular Zveibil. Rio de Janeiro: IBAM, 2001.

PREFEITURA MUNICIPAL DE MAMBORÊ. Plano Diretor de Mamborê, 2014.

SECRETARIA DE MEIO AMBIENTE. Plano de Gerenciamento de Resíduos Sólidos do Município de Mamborê. 2006.

RODRIGUES, A. M. Produção e consumo do e no espaço: problemática atual urbana. São Paulo: Hucitec, 1998.

SNIS. Sistema Nacional de Informação sobre Saneamento - Resíduos Sólidos. Dados disponíveis por municípios. 2013. Disponível em: <http://www.snis.gov.br $>$. Acesso em: 15 jan. 2019.

STRAUCH, M.; ALBUQUERQUE, P. P. (Org.). Resíduos: como lidar com os recursos naturais. São Leopoldo: Ed. Oikos, 2008. 